\title{
Distinctive clinical features of human bocavirus in children younger than 2 years
}

\author{
Yoko Moriyama $\cdot$ Hiromichi Hamada $\cdot$ Mineyuki Okada $\cdot$ Nozomi Tsuchiya $\cdot$ \\ Hiromi Maru • Yuri Shirato • Yasuhiro Maeda • Yosuke Hirose • Masaki Yoshida • \\ Yoh Omura • Takafumi Honda • Ayako Muto • Kitami Hayashi • Masaru Terai
}

Received: 22 December 2009 / Accepted: 25 February 2010 / Published online: 10 April 2010

(C) The Author(s) 2010. This article is published with open access at Springerlink.com

\begin{abstract}
Background and objective Clinical characteristics of human bocavirus $(\mathrm{HBoV})$ infection have been studied worldwide, but their importance of those characteristics remains unknown. We investigated distinctive clinical features of $\mathrm{HBoV}$-positive children with lower respiratory tract infection (LRTI).

Methods and results During April 2007-July 2009, for 402 hospitalized children younger than 2 years with LRTI, we prospectively examined virus genomes in nasopharyngeal swabs for $\mathrm{HBoV}$, respiratory syncytial virus (RSV), rhinovirus, metapneumovirus, parainfluenzavirus, and adenovirus. The HBoV genomes were identified in 34 patients $(8.5 \%)$. Clinical and laboratory data of $\mathrm{HBoV}$-positive and other virus/bacteria-negative patients $(n=18)$ were analyzed and compared with data of RSV-single positive patients $(n=99)$. The seasonal distribution of $\mathrm{HBoV}$ exhibits a concentration of cases during March-September, with most RSV cases occurring during winter in Japan. The minimum age of HBoV-positive patients was 5 months, although 44 patients (44\%) with RSV were younger than 6 months. The main clinical features were respiratory distress and hypoxia. Hypoxia advances within 3 days after onset. The mean
\end{abstract}

Y. Moriyama $\cdot$ H. Hamada $(\bowtie) \cdot N$. Tsuchiya $\cdot$ Y. Shirato $\cdot$

Y. Maeda $\cdot$ Y. Hirose $\cdot$ M. Yoshida $\cdot$ Y. Omura $\cdot$ T. Honda

A. Muto $\cdot$ K. Hayashi $\cdot$ M. Terai

Department of Pediatrics,

Tokyo Women's Medical University Yachiyo Medical Center,

477-96, Owada-shinden,

Yachiyo, Chiba 276-8524, Japan

e-mail: h-hamada@tymc.twmu.ac.jp

M. Okada $\cdot$ H. Maru

Chiba Prefectural Institute of Public Health,

Chiba, Japan oxygen saturation on arrival was $92.8 \%$, which was significantly lower than that in patients with RSV $(p<$ 0.001 ). White blood cell counts were similar among groups. However, the percentage of neutrophils in white blood cells were significantly higher in $\mathrm{HBoV}$-positive patients (62 vs. $45 \%, p<0.001)$. Their prognoses were good. Their hospital stays were 6.6 days.

Conclusions $\mathrm{HBoV}$-single positive patients show several clinical characteristics, such as seasonality, age, hypoxia, and neutrophilia, which differ from those with RSV infection.

Keywords Human bocavirus - Respiratory syncytial virus . Lower respiratory tract infection $\cdot$ Infant

Pneumonia and other lower respiratory tract infections (LRTIs) are a major cause of mortality and morbidity in infants and young children [6]. During the past decade, detection of various respiratory viruses has improved by virtue of new molecular techniques and the availability of monoclonal antibodies for many viral species. New viruses such as human metapneumovirus (hMPV) [28], severe acute respiratory syndrome coronavirus (SARS-CoV) $[11$, $16,23]$, and human bocavirus ( $\mathrm{HBoV})$ are reportedly major pathogens of human respiratory infection.

Since the detection of $\mathrm{HBoV}$ from respiratory tract samples from Swedish infants and children with LRTI [3], reports related to $\mathrm{HBoV}$ have been published around the world. Epidemiological data show that $\mathrm{HBoV}$ is present on every continent with different incidence rates and seasonality. In fact, $\mathrm{HBoV}$ is detected year round, with rates of $0.5-19 \%$ in patients with LRTI $[2,7,13,15,26]$. Recently, this virus is propagated in an in vitro culture system [10]. No animal model of infection has been established. Nevertheless, the 
fact that $\mathrm{HBoV}$ is not detected randomly in materials but is detected significantly more often in the absence of other viruses suggests that $\mathrm{HBoV}$ is a causative agent of previously unexplained respiratory tract infections [25].

Several epidemiological and clinical investigations have assessed $\mathrm{HBoV}$-related illness; its clinical features have been reported as resembling those of respiratory syncytial virus (RSV) and human metapneumovirus (hMPV) infections [5]. Nevertheless, few data are available related to physical characteristics and clinical severity for children with HBoV-positive LRTIs [19]. To determine precise clinical characteristics in $\mathrm{HBoV}$-positive patients, we prospectively collected numeric data for the clinical status of young children with LRTI and analyzed them. Results showed several unique physical characteristics in HBoVpositive patients that differed significantly from those in RSV-positive patients.

\section{Patients and methods}

\section{Patients}

The study population comprised 402 children younger than 2 years who were hospitalized with lower respiratory tract disease at some time during March 2007-July 2008 (248 male, mean age 11.6 months \pm standard deviation 6.5). Informed consent was obtained from parents or guardians. Of the patients, $93(23.2 \%)$ were younger than 6 months. This study was approved by the Ethical Committee of Tokyo Women's Medical University (\#1492).

On admission, the medical history and physical characteristics of the children were recorded systematically. For this study, LRTI was defined as the presence of wheezing, crackling rales, dyspnea, and/or obstruction of the airways, with or without fever. All patients with suspected LRTI underwent chest radiography. Pneumonia was defined as the presence of focal infiltration or consolidation in the lung by chest radiography. Blood samples were obtained to measure quantities of whole white blood cells (WBCs) as well as neutrocytes, lymphocytes, monocytes, and eosinophils. Serum samples were obtained to measure C-reactive proteins.

Oxygen saturation of the children was monitored during the hospital stay. Oxygen therapy was provided to achieve oxygen saturation $\geq 95 \%$. A physician judged the bronchodilator use and administration of antibiotics for each patient according to physical findings and laboratory data.

Nucleic acid extraction and amplification

A nasopharyngeal swab was collected from each patient and then dipped into saline and stored at $-80^{\circ} \mathrm{C}$ until nucleic acid extraction. Nucleic acid was extracted using a kit (High Pure Viral Nucleic Acid Kit; Roche Diagnostics Corp., Mannheim, Germany) according to the manufacturer's recommended procedures. Then $\mathrm{PCR} /$ reverse-transcription PCR (RT-PCR) was performed using previously described methods with slight modifications $[1,3,4,9,22$, 24]. Briefly, for the RNA viruses, a superscript one-step RTPCR system (Invitrogen Corp., Carlsbad, CA, USA) was used for reverse-transcription and first-round PCR with virus specific primers under the manufacturer's instructions. For DNA viruses and also nested PCR, Ex Taq DNA polymerase (Takara Bio Inc., Shiga, Japan) was used along with the manufacturer's supplied buffer under the appropriate thermal cycle conditions for each primer. Each sample was examined for RSV, rhinovirus (RV), hMPV, $\mathrm{HBoV}$, adenovirus (AdV), and parainfluenzavirus (PIV). Following amplification, PCR products were separated on the $1.5 \%$ agarose gel with Tris-boric acid-EDTA buffer and visualized with SYBR-green (Cambrex Corp., Rockland, ME, USA) under a UV transilluminator. The PCR products were purified; their nucleic acid sequences were determined to confirm PCR results. Nucleotide sequences were processed using software (GENETYX) and compared to nucleotide sequences of the DNA database using a BLAST system [20].

\section{Statistical analysis}

All data were described as mean $(m) \pm$ standard deviation (SD). Parametric data were analyzed using Student's $t$-test. A $p$ value of $<0.05$ was considered statistically significant. All analyses were performed using software (JMP ver.8; SAS Institute Inc., NC, USA).

\section{Results}

Frequency and seasonality of human bocavirus detection

Table 1 presents infectious agents detected in the study population. We detected at least one virus agent in 226 $(56.2 \%)$ of the 402 children; 36 patients $(9.0 \%)$ were coinfected with different viruses. No virus was detected in 140 patients $(34.8 \%)$.

During the same study period, we prospectively collected swabs from 30 age-matched children with no respiratory symptoms and analyzed them similarly. Except for one patient, who was positive for rhinovirus, no virus was detected in these 30 children.

In hospitalized infants and young children aged 0 24 months, RSV was the most commonly detected virus. Of 402 patients, 111 were RSV-positive (27.6\%). In 99 out of 111 patients with RSV, PCR results for other viruses were negative. Bocavirus was the fourth most common virus in 
Table 1 Viruses detected in 402 patients under 2 years of age with lower respiratory tract infection
$R S V$ respiratory syncytial virus, $R V$ rhinovirus, $h M P V$ human metapneumovirus, $H B o V$ human bocavirus, $P I V$ parainfluenza virus, $A d V$ adenovirus

\begin{tabular}{|c|c|c|}
\hline & Number & Percent \\
\hline Patients infected with a single pathogen & 226 & $56.2 \%$ \\
\hline RSV & 99 & $24.6 \%$ \\
\hline $\mathrm{RV}$ & 41 & $10.2 \%$ \\
\hline hMPV & 37 & $9.2 \%$ \\
\hline $\mathrm{HBoV}$ & 20 & $5.0 \%$ \\
\hline PIV & 15 & $3.7 \%$ \\
\hline $\mathrm{AdV}$ & 14 & $3.5 \%$ \\
\hline Patients infected with more than one pathogen & 36 & $9.0 \%$ \\
\hline $\mathrm{HBoV}+\mathrm{PIV}$ & 5 & $1.2 \%$ \\
\hline $\mathrm{HBoV}+\mathrm{RV}$ & 4 & $1.0 \%$ \\
\hline $\mathrm{HBoV}+\mathrm{HMPV}$ & 2 & $0.5 \%$ \\
\hline $\mathrm{HBoV}+\mathrm{AdV}$ & 2 & $0.5 \%$ \\
\hline $\mathrm{HBoV}+\mathrm{RSV}$ & 1 & $0.2 \%$ \\
\hline $\mathrm{RSV}+\mathrm{RV}$ & 6 & $1.5 \%$ \\
\hline $\mathrm{RSV}+\mathrm{AdV}$ & 3 & $0.7 \%$ \\
\hline $\mathrm{PIV}+\mathrm{RV}$ & 2 & $0.5 \%$ \\
\hline $\mathrm{hMPV}+\mathrm{AdV}$ & 3 & $0.7 \%$ \\
\hline $\mathrm{hMPV}+\mathrm{RV}$ & 2 & $0.5 \%$ \\
\hline hMPV+RSV & 1 & $0.2 \%$ \\
\hline hMPV+PIV & 1 & $0.2 \%$ \\
\hline $\mathrm{AdV}+\mathrm{RV}$ & 1 & $0.2 \%$ \\
\hline $\mathrm{AdV}+\mathrm{PIV}$ & 1 & $0.2 \%$ \\
\hline $\mathrm{AdV}+\mathrm{hMPV}+\mathrm{RV}$ & 1 & $0.2 \%$ \\
\hline $\mathrm{RSV}+\mathrm{AdV}+\mathrm{RV}$ & 1 & $0.2 \%$ \\
\hline Patients not infected with any studied pathogen & 140 & $34.8 \%$ \\
\hline Total & 402 & $100 \%$ \\
\hline
\end{tabular}

the study population. Of the hospitalized children, 34 $(8.5 \%)$ were $\mathrm{HBoV}$ positive. In 14 of 34 patients $(41 \%)$, some other virus and $\mathrm{HBoV}$ were double positive (five with PIV, four with rhinovirus, two with hMPV, two with AdV, and one with RSV). In the other 20 patients (59\%), PCR results for other viruses were negative. Of the 20 patients, two showed co-infection with Streptococcus pneumoniae, as diagnosed from sputum culture. We specifically examined the other 18 patients for the analysis of clinical features associated with $\mathrm{HBoV}$ infection.

Seasonal distribution of $\mathrm{HBoV}$ was noted during MarchSeptember (Fig. 1a). During March-May 2008, HBoVpositive patients accounted for $37 \%$ of all hospitalized children with LRTIs, suggesting that $\mathrm{HBoV}$ is a common etiologic agent causing LRTIs during spring and early summer in the area of Tokyo, Japan $\left(35^{\circ} \mathrm{N}\right)$.

Clinical manifestations of LRTI patients positive for human bocavirus

The median age of HBoV-positive and other virus/bacterianegative patients $(n=18)$ was 14 months. The minimum age was 5 months (Fig. 2a); this patient was the only one under 6 months of age who had HBoV. Four patients had underlying diseases. One had Down syndrome, with congenital heart disease and pulmonary hypertension. The other two patients had chronic respiratory conditions: one was an extremely low birth weight infant developing chronic lung disease and the other with bronchial asthma. The last patient had mental retardation.

Of 18 patients, seven (39\%) were diagnosed with acute pneumonia. Chest X-rays of seven patients showed reticulonodular infiltrates in one or several segments. Two patients had lobar atelectasis. The other 11 patients were diagnosed with acute bronchitis (Table 2).

The most common symptoms of $\mathrm{HBoV}$-positive patients were cough and fever, which were found in all 18 patients $(100 \%)$. High fever over $38.5^{\circ} \mathrm{C}$ was found in 13 patients (72\%). The mean maximum temperature was $38.9 \pm 0.8^{\circ} \mathrm{C}$. Wheezing and respiratory distress were found in 14 patients (78\%). One patient had diarrhea; the other 17 patients had no gastrointestinal manifestation.

Hypoxia was a characteristic feature in HBoV-positive patients (Table 2). On admission, the mean oxygen 

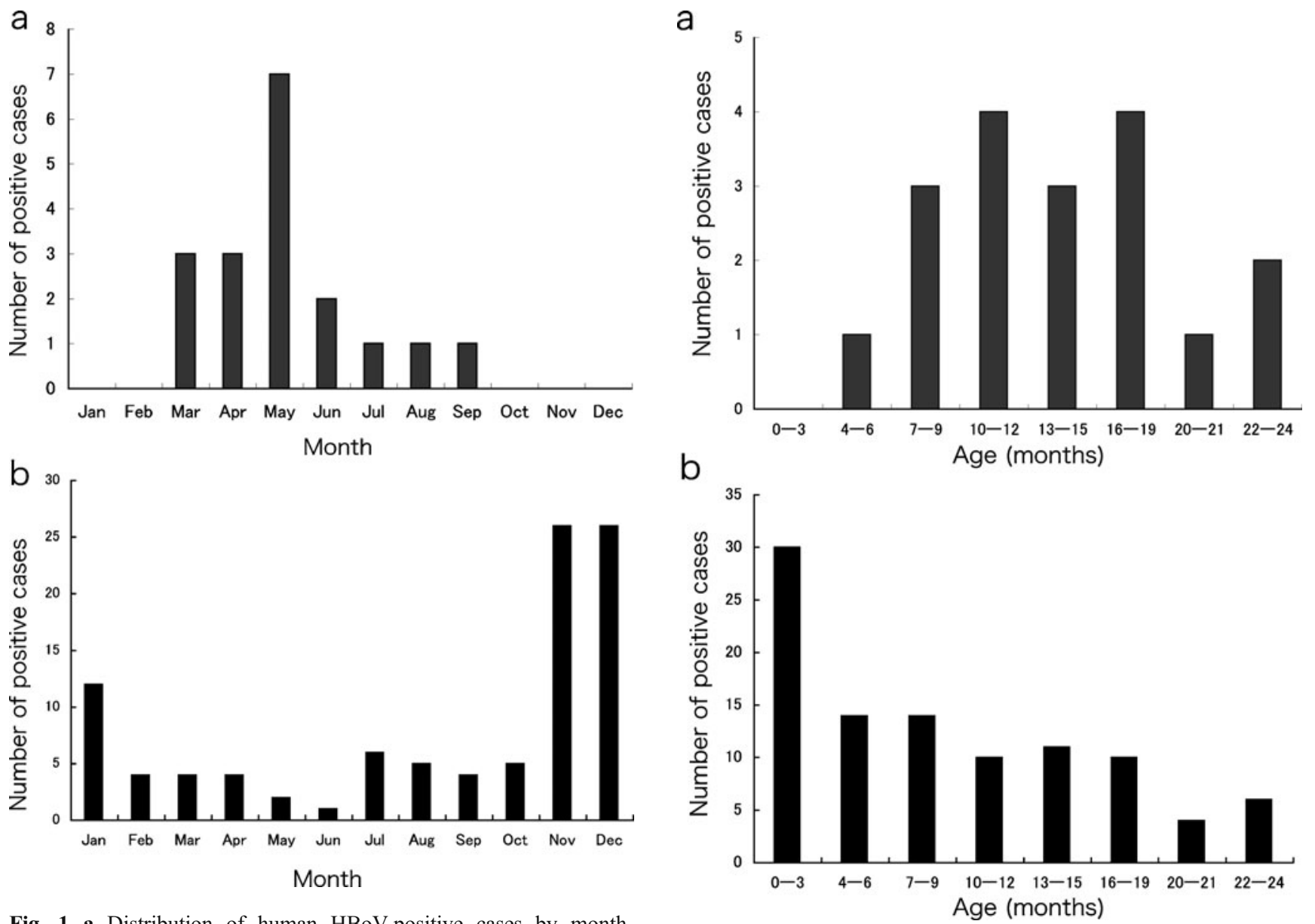

Fig. 1 a Distribution of human HBoV-positive cases by month. b Distribution of RSV-positive cases by month

saturation in $\mathrm{HBoV}$-positive patients was $92.8 \pm 4.8 \%$. The mean period from onset of illness to admission was $3.0 \pm$ 1.1 days. For 17 of 18 patients, the main reason for admission was hypoxia and/or respiratory distress. Actually, 14 patients $(78 \%)$ needed oxygen therapy. No patient required mechanical ventilation.

The clinical course was good except for that of one infant, who had extremely low birth weight and had chronic lung disease. The length of the hospital stay was $6.6 \pm$ 3.2 days.

Comparison of clinical data of patients positive for $\mathrm{HBoV}$ with those of patients positive for RSV

We compared clinical data of the 18 patients with the data of hospitalized patients who were positive for RSV and negative for other viruses in the same study period $(n=99$, Table 2).

A seasonal distribution of $\mathrm{HBoV}$ was noted during March-September. However, RSV was identified all year round; its epidemic peak was November-December (Fig. 1b). Age distributions of the two groups differed. One patient had $\mathrm{HBoV}$ at less than 6 months of age,

Fig. 2 a Age (months) of patients with detected HBoV. b Age (months) of patients with detection of RSV

although 44 patients with RSV (44\%) were less than 6 months of age (Fig. 2b).

The period from disease onset to admission was significantly shorter among $\mathrm{HBoV}$-positive patients than

Table 2 Clinical data in children positive with $\mathrm{HBoV}$ and in children positive with RSV

\begin{tabular}{llll}
\hline & $\begin{array}{l}\mathrm{HBoV} \\
n=18\end{array}$ & $\begin{array}{l}\mathrm{RSV} \\
n=99\end{array}$ & $p$ value \\
\hline Age (months) & $14.1 \pm 5.1$ & $8.9 \pm 7.0$ & 0.0008 \\
Gender (male \%) & 78 & 81 & $\mathrm{NS}$ \\
Diagnosis (pneumonia \%) & 39 & 34 & $\mathrm{NS}$ \\
Day on admission & $3.0 \pm 1.1$ & $4.0 \pm 1.4$ & 0.008 \\
Oxygen saturation $(\%)$ & $92.8 \pm 4.8$ & $95.7 \pm 2.9$ & 0.0004 \\
Highest temperature $\left({ }^{\circ} \mathrm{C}\right)$ & $38.9 \pm 0.8$ & $38.7 \pm 1.8$ & $\mathrm{NS}$ \\
WBC $\left(\times 10^{3}\right.$ cells $\left./ \mathrm{mm}^{3}\right)$ & $11.4 \pm 2.9$ & $11.4 \pm 4.6$ & $\mathrm{NS}$ \\
Neutrophils $(\%)$ & $62 \pm 15$ & $45 \pm 18$ & $<0.0001$ \\
CRP $(\mathrm{mg} / \mathrm{dL})$ & $2.62 \pm 2.55$ & $1.96 \pm 2.95$ & $\mathrm{NS}$ \\
Days in hospital (days) & $6.6 \pm 3.2$ & $6.3 \pm 1.8$ & $\mathrm{NS}$ \\
\hline
\end{tabular}

$C R P$ C-reactive protein, $N S$ not significant, $W B C$ white blood cell 
among RSV-positive patients ( $p=0.008$, Table 2$)$. Furthermore, the mean oxygen saturation in HBoV-positive patients on admission was significantly lower than that in RSV-positive patients $(p=0.0004$, Table 2$)$. White blood cell (WBC) counts in these two groups were similar. However, the percentage of neutrophils in WBCs were significantly higher in HBoV-positive patients than in RSVpositive patients $(p<0.0001$, Table 2$)$. The C-reactive protein in $\mathrm{HBoV}$-positive patients was similar to that of RSV-positive patients (Table 2).

The hospital stay lengths of the groups were similar. No patient in either group required mechanical ventilation.

\section{Discussion}

This prospective study reveals several characteristics of HBoV-positive LRTI in young children: seasonality, age distribution, hypoxia, neutrophilia, and findings in chest radiography. Comparison of clinical features to those in patients with RSV infection, which is the major etiologic agent in LRTI of young children, showed that major clinical manifestations such as wheezing and respiratory distress were similar in both groups of patients. However, several physical characteristics of HBoV-positive patients differed significantly from those of RSV-positive patients. To describe clinical manifestations of children with LRTIs with $\mathrm{HBoV}$ clearly, we selected $\mathrm{HBoV}$-positive and other virus/bacteria-negative patients.

Regarding the HBoV seasonality, its peak was similar to that identified in a previous study in northern Japan. In the study, HBoV-positive patients were most prevalent during January-May. The peak occurred during April-May in Japan [17]. The seasons are important diagnostic information in Japan. In France, the seasonal distribution is November-June; the peak occurs in March-April [15], which resembles the circumstances in Japan. In Hong Kong and Thailand, the peak seasons were in fall and winter, respectively $[8,14]$.

Specific examination of extremely young patients revealed a clear difference in the age distribution of HBoV-positive patients from that of RSV. In RSV-positive patients, $44 \%$ of all patients were younger than 6 months. In contrast, the minimum age of $\mathrm{HBoV}$-positive patients was 5 months. Endo et al. measured the levels of the antibody in human serum samples aged from 0 months to 41 years and reported that the seropositive rate was lowest in the age group of 6-8 months [12]. These data suggest that infants younger than 6 months might be protected from $\mathrm{HBoV}$ infection.

The main clinical features in HBoV-positive patients are respiratory distress and hypoxia, which are frequently observed in LRTI patients with RSV. In our study, oxygen saturation on admission shows that hypoxia was more severe in HBoV-positive patients than in RSV-positive patients. Moreover, the short duration from disease onset to admission shows that respiratory distress and hypoxia progress rapidly in $\mathrm{HBoV}$-positive patients. Oikawa et al. recently reported a severe case with $\mathrm{HBoV}$ associated with plastic bronchitis, which necessitated mechanical ventilation [21]. Many previous reports have not described severe cases of HBoV infection; however, the sample size is small and the studies were retrospective. In our study, one out of 18 patients had severe pneumonia and remained hospitalized for 19 days. A larger number of cases with HBoVpositive LRTI must be accumulated to discuss the disease severity. Patients with RSV infection sometimes need intensive care. Pediatricians have specifically addressed the care and protection of this infection. One reason is that the RSV infection is frequently found in infants who are younger than 3 months. Furthermore, patients younger than 3 months often require intensive care. In contrast, the minimum age of $\mathrm{HBoV}$-positive patient is 5 months in our study. Therefore, the difference in the age of patients might affect the disease severity.

Laboratory data show that the rate of neutrophils in WBCs is significantly higher in $\mathrm{HBoV}$-positive patients, which is a unique characteristic of HBoV-positive LRTI. It is particularly interesting that the rate of neutrophils in hMPV-positive patients is similar to that in RSV-positive patients (data not shown). This parameter might strongly support clinical diagnosis of LRTI with HBoV. Acute hypoxia induces a differential response in peripheral blood neutrophils and lymphocytes, resulting in neutrophilia and lymphopenia [27]. Hypoxia might be associated with neutrophilia in $\mathrm{HBoV}$-positive patients. However, the precise mechanisms for neutrophilia remain unclear.

Recently, a high co-infection rate is under discussion in $\mathrm{HBoV}$-positive respiratory infection [17, 18]. Previous reports have presented the possibility that $\mathrm{HBoV}$ detection in respiratory tract samples reflects asymptomatic persistence or prolonged viral shedding [26]. Although results of the present study also show a high co-infection rate, clinical characteristics in $\mathrm{HBoV}$-single positive patients strongly suggest the pathogenic potential of $\mathrm{HBoV}$ in young children with LRTIs.

This study did not survey all respiratory viruses such as coronavirus or influenza virus. Quantification of viral loads might provide useful information, especially information that would be useful to analyze co-infection cases more clearly.

In conclusion, the results of our study support that $\mathrm{HBoV}$ is an important causative agent in young children hospitalized with LRTI in Japan. In young children, HBoVpositive patients show several clinical characteristics that differ from those with RSV. More cases should be 
examined to confirm clinical manifestations and prognoses of HBoV-associated LRTIs.

Acknowledgments This study was supported by a grant from the Japanese Society for Pediatric Infectious Diseases (H.H.) and by a grant from the Chiba Serum Institute Memorial Fund (H.H.).

Conflict of interest The authors declare no conflict of interest.

Open Access This article is distributed under the terms of the Creative Commons Attribution Noncommercial License which permits any noncommercial use, distribution, and reproduction in any medium, provided the original author(s) and source are credited.

\section{References}

1. Aguilar JC, Pérez-Breña MP, García ML, Cruz N, Erdman DD, Echevarría JE (2000) Detection and identification of human parainfluenza viruses 1, 2, 3 and 4 in clinical samples of pediatric patients by multiplex reverse transcription-PCR. J Clin Microbiol 38:1191-1195

2. Allander T, Jartti T, Gupta S, Niesters HG, Lehtinen P, Osterback R, Vuorinen T, Waris M, Bjerkner A, Tiveljung-Lindell A, van den Hoogen BG, Hyypiä T, Ruuskanen O (2007) Human bocavirus and acute wheezing in children. Clin Infect Dis 44:904-910

3. Allander T, Tammi MT, Eriksson M, Bjerkner A, Tiveljung-Lindell A, Andersson B (2005) Cloning of a human parvovirus by molecular screening of respiratory tract samples. Proc Natl Acad Sci USA 102:12891-12896

4. Atmar RL, Georghiou PR (1993) Classification of respiratory tract picornavirus isolates as enteroviruses or rhinoviruses by using reverse transcription-polymerase chain reaction. J Clin Microbiol 31:2544-2546

5. Brieu N, Guyon G, Rodière M, Segondy M, Foulongne V (2008) Human bocavirus infection in children with respiratory tract disease. Pediatr Infect Dis J 27:969-973

6. Bryce J, Boschi-Pinto C, Shibuya K, Black RE (2005) WHO estimates of the causes of death in children. Lancet 365:1147-1152

7. Calvo C, García-García ML, Pozo F, Carvajal O, Perez-Brena P, Casas I (2008) Clinical characteristics of human bocavirus infections compared with other respiratory viruses in Spanish children. Pediatr Infect Dis J 27:677-680

8. Chieochansin T, Samransamruajkit R, Chitinimitkul S, Payungporn S, Hiranras T, Theamboonlers A, Poovorawan Y (2008) Human bocavirus $(\mathrm{HBoV})$ in Thailand: clinical manifestations in a hospitalized pediatric patient and molecular virus characterization. J Infect 56:137-142

9. Coiras MT, Pérez-Breña MP, García ML, Casas I (2003) Simultaneous detection of influenza $\mathrm{A}, \mathrm{B}$, and $\mathrm{C}$ viruses, respiratory syncytial virus, and adenoviruses in clinical samples by multiplex reverse transcription nested-PCR assay. J Med Virol 69:132-144

10. Dijkman R, Koekkoek SM, Molemkamp R, Schildgen O, van den Hoek L (2009) Human bocavirus can be cultured in differentiated human airway epithelial cells. J Virol 83:7739-7748

11. Drosten C, Günther S, Preiser W, van der Werf S, Brodt HR, Becker S, Rabenau H, Panning M, Kolesnikova L, Fouchier RA, Berger A, Burguière AM, Cinatl J, Eickmann M, Escriou N, Grywna K, Kramme S, Manuguerra JC, Müller S, Rickerts V,
Stürmer M, Vieth S, Klenk HD, Osterhaus AD, Schmitz H, Doerr HW (2003) Identification of a novel coronavirus in patients with severe acute respiratory syndrome. N Engl J Med 348:1967-1976

12. Endo R, Ishiguro N, Kikuta H, Teramoto S, Shirkoohi R, Ma X, Ebihara T, Ishiko H, Ariga T (2007) Seroepidemiology of human bocavirus in Hokkaido Prefecture, Japan. J Clin Microbiology 45:3218-3223

13. Foulongne V, Rodiere M, Segondy M (2006) Human bocavirus in children. Emerg Infect Dis 12:862-863

14. Ip M, Nelson EA, Cheuk ES, Leung E, Sung R, Chan PK (2008) Pediatric hospitalization of acute respiratory tract infections with Human Bocavirus in Hong Kong. J Clin Virol 42:72-74

15. Jacques J, Moret H, Renois F, Leveque N, Motte J, Andreoletti L (2008) Human bocavirus quantitative DNA detection in French children hospitalized for acute bronchitis. J Clin Virol 43:142-147

16. Ksiazek TG, Erdman D, Goldsmith CS, Zaki SR, Peret T, Emery S, Tong S, Urbani C, Comer JA, Lim W, Rollin PE, Dowell SF, Ling AE, Humphrey CD, Shieh WJ, Guarner J, Paddock CD, Rota P, Fields B, DeRisi J, Yang JY, Cox N, Hughes JM, LeDuc JW, Bellini WJ, Anderson LJ (2003) A novel coronavirus associated with severe acute respiratory syndrome. N Engl J Med 348:1953-1966

17. Ma X, Endo R, Ishiguro N, Ebihara T, Ishiko H, Ariga T, Kikuta H (2006) Detection of Human Bocavirus in Japanese children with lower respiratory tract infections. J Clin Microbiology 44:1132-1134

18. Manning A, Russell V, Eastick K, Leadbetter GH, Hallam N, Templeton K, Simmons P (2006) Epidemiological profile and clinical associations of human bocavirus and other human parvoviruses. J Infect Dis 194:1283-1290

19. Midulla F, Scagnolari C, Bonci E, Pierangeli A, Antonelli G, De Angelis D, Belardi R, Moretti C (2008) Respiratory syncytial virus, human bocavirus and rhinovirus bronchiolitis in infants. Arch Dis Child. doi:10.1136/adc.2008.153361

20. National Center for Biotechnology Information. Basic local alignment search tool. Available via BLAST http://www.ncbi. nlm.nih.gov/BLAST/

21. Oikawa J, Ogita J, Ishiwada N, Okada T, Endo R, Ishiguro N (2009) Human bocavirus DNA detected in a boy with plastic bronchitis. Ped Infect Dis J 28:1035-1036

22. Okada M, Ogawa T, Kubonoya H, Yoshizumi H, Shinozaki K (2007) Detection and sequence-based typing of human adenoviruses using sensitive universal primer sets for the hexon gene. Arch Virol 152:1-9

23. Peiris JS, Lai ST, Poon LL, Guan Y, Yam LY, Lim W, Nicholls J, Yee WK, Yan WW, Cheung MT, Cheng VC, Chan KH, Tsang DN, Yung RW, Ng TK, Yuen KY (2003) Coronavirus as a possible cause of severe acute respiratory syndrome. Lancet 361:1319-1325

24. Peret TC, Boivin G, Li Y, Couillard M, Humphrey C, Osterhaus AD, Erdman DD, Anderson LJ (2002) Characterization of human metapneumoviruses isolated from patients in north America. J Infect Dis 185:1660-1663

25. Schildgen O, Müller A, Allander T, Mackay IM, Volz S, Kupfer B, Simon A (2008) Human Bocavirus: passenger or pathogen in acute respiratory tract infections? Clin Microbiol Rev 21:291-304

26. Smuts H, Hardie E (2006) Human bocavirus in hospitalized children, South Africa. Emerg Infect Dis 12:848-850

27. Thake CD, Mian T, Garnham AW, Mian R (2004) Leukocyte counts and neutrophil activity during $4 \mathrm{~h}$ of hypocapnic hypoxia equivalent to $4000 \mathrm{~m}$. Aviat Space Environ Med 9:811-817

28. van den Hoogen BG, de Jong JC, Groen J, Kuiken T, de Groot R, Fouchier RA, Osterhaus AD (2001) A newly discovered human pneumovirus isolated from young children with respiratory tract disease. Nat Med 7:719-724 